\author{
A. Z. Jamurtas $\cdot$ Y. Koutedakis - V. Paschalis \\ T. Tofas · C. Yfanti - A. Tsiokanos · G. Koukoulis \\ D. Kouretas · D. Loupos
}

\title{
The effects of a single bout of exercise on resting energy expenditure and respiratory exchange ratio
}

\begin{abstract}
We investigated the effects of a single bout of aerobic and resistance exercise of similar relative intensity and duration on resting energy expenditure (REE) and substrate utilisation. Ten young healthy males volunteered [age $22(1.8)$ years, weight $76(7.9) \mathrm{kg}$, height $176(4.1) \mathrm{cm}$, percentage body fat $10.5(4.0) \%$; mean (SEM)]. They randomly underwent three conditions in which they either lifted weights for $60 \mathrm{~min}$ at $70-75 \%$ of 1-RM (WL), ran for $60 \mathrm{~min}$ at $70-75 \%$ of maximal oxygen intake (R) or did not exercise (C). REE and substrate utilisation, determined via respiratory exchange ratio $(R)$, were measured prior to exercise, and $10,24,48$ and $72 \mathrm{~h}$ post-exercise. It was revealed that REE was significantly elevated $(P<0.05) 10$ and $24 \mathrm{~h}$ after the end of WL $[2,124(78)$ and 2,081 (76) kcal, respectively] compared to pre-exercise [1,972 (82) kcal]. REE was also significantly increased $(P<0.05) 10$ and $48 \mathrm{~h}$ after the completion of $\mathrm{R}[2,150$ (73) and 1,995 (74) $\mathrm{kcal}$, respectively] compared to pre-exercise data $[1,862(70) \mathrm{kcal}]$. $R$ was lower 10 and $24 \mathrm{~h}$ following
\end{abstract}

\footnotetext{
A. Z. Jamurtas $(\bowtie) \cdot$ Y. Koutedakis $\cdot$ T. Tofas $\cdot$ C. Yfanti A. Tsiokanos

Department of Physical Education and Sport Science, Thessaly University, 42100 Trikala, Greece E-mail: ajamurt@pe.uth.gr

Tel.: + 30-24310-47054

Fax: + 30-24310-47042

Y. Koutedakis

School of Sport, Performing Arts and Leisure,

Wolverhampton University, Walshall, UK

G. Koukoulis

Department of Medicine, School of Health Sciences, Thessaly University, 42100 Larisa, Greece

D. Kouretas

Department of Biochemistry and Biotechnology, School of Health Sciences, Thessaly University, 42100 Larisa, Greece

D. Loupos

Department of Physical Education and Sports Science, Aristotle University of Thessaloniki,

54006 Thessaloniki, Greece
}

either WL or R $[0.813(0.043) ; 0.843(0.040)$ and $0.818(0.021) ; 0.832(0.021)$, respectively] compared to baseline measurements $[0.870(0.025)$ and $0.876(0.04)$, respectively]. Creatine kinase was significantly elevated $(P<0.05) 24 \mathrm{~h}$ after both WL and R, whereas delayed onset muscle soreness became significantly elevated $(P<0.05) 24 \mathrm{~h}$ after only WL. There were no significant changes for any treatment in thyroid hormones $\left(\mathrm{T}_{3}\right.$ and $\mathrm{T}_{4}$ ). These results suggest that a single bout of either WL or $\mathrm{R}$ exercise, characterised by the same relative intensity and duration, increase REE and fat oxidation for at least $24 \mathrm{~h}$ post-exercise.

Keywords Acute exercise - Fat oxidation ·

Metabolism $\cdot$ Run $\cdot$ Weight-lifting

\section{Introduction}

Elevated post-exercise energy expenditure has a significant role in body mass control (Schuenke et al. 2002; Sedlock et al. 1989). Previous research has shown that a single bout of weight-lifting (WL) exercise leads to elevated post-exercise energy expenditure that can last approximately $15 \mathrm{~h}$ (Melby et al. 1993). Furthermore, reports indicate that, in both young as well as older individuals, a single bout of WL exercise keeps resting metabolic rate elevated $48 \mathrm{~h}$ post-exercise (Schuenke et al. 2002; Williamson and Kirwan 1997). In addition, there have been numerous studies indicating that WL and cardiovascular training can affect the metabolic rate leading to higher resting energy expenditure (REE) (Binzen et al. 2001; Dolezal and Potteiger 1998; Poehlman et al. 1992).

The reasons for the alterations in REE are not clear. There have been suggestions that the enhancement of REE could be related, for instance, to increased protein synthesis (MacDougal et al. 1995), increased thermogenesis affected by the thyroid hormones, particularly triidiothyronine $\left(\mathrm{T}_{3}\right)$ (Lebon et al. 2001), and/or increased sympathetic nervous system activity (Pratley 
et al. 1994). However, the reported elevation in REE following either WL or cardiovascular training programmes are not directly related to the exercise programmes themselves but could be attributed to the residual effects of the last exercise session (Bullough et al. 1995; Melby et al. 1993).

Several studies have examined the metabolic effects of exercise. For example, endurance running $(\mathrm{R})$ and resistance exercise training can result in higher fat oxidation (Poehlman and Melby 1998), which in turn has been associated with increased sympathetic nervous system activity (Poehlman et al. 1994). Furthermore, enhancement of post-exercise lipid oxidation (15 h post-exercise) has been found following a single bout of WL exercise (Melby et al. 1993). However, the degree of REE and fat oxidation perturbations over time, following a single bout of different modes of exercise characterised by the same relative intensity and duration, are not entirely clear. Therefore, the purpose of this study was to assess changes in REE and fat oxidation 10, 24, 48 and $72 \mathrm{~h}$ following a single bout of WL and aerobic R exercise.

$\mathrm{WL}$ and $\mathrm{R}$ of moderate intensity represent two popular modes of exercise and are often suggested as means for fitness improvements and weight management (American College of Sports Medicine 2000). Since the net caloric cost for WL is different than that of $\mathrm{R}$ (Burleson et al. 1998), it was not our intention to evaluate the differences between the two modes of exercise but rather to examine the delaying effects of acute exercise on REE and substrate utilisation perturbations.

\section{Methods}

\section{Subject characteristics}

Ten young males volunteered to participate in this study, which was approved by the Institutional Review Board of Thessaly University. Each subject read and signed an informed consent form prior to participation in the study. Exclusion criteria included smoking, supplements or medication known to affect REE, and consumption of drinks containing caffeine or alcohol. Subjects were instructed not to exercise for 3 days prior to data collection.

Body mass was measured to the nearest $0.5 \mathrm{~kg}$ (Seca Beam Balance 710) with subjects lightly dressed and barefooted. Standing height was measured to the nearest $0.5 \mathrm{~cm}$ (Seca Stadiometer 208). Percentage body fat was calculated according to published guidelines (American College of Sports Medicine 2000), i.e. from seven skinfold measures (average of two measurements of each site) using a Harpenden (John Bull, UK) calliper. The subjects' physical characteristics are given in Table 1 .

\section{Procedures}

Prior to data collection, the individual 1-repetition maximum (1-RM) was established following published
Table 1 Physical characteristics of the subjects

\begin{tabular}{lll}
\hline Variable & Mean & SEM \\
\hline Age (years) & 21.8 & 1.8 \\
Height (cm) & 175.6 & 4.1 \\
Body mass (kg) & 76.2 & 7.9 \\
Body fat (\%) & 10.5 & 4.0 \\
$\dot{V} \mathrm{O}_{2 \max }\left(\mathrm{m} \mathrm{kg}^{-1} \mathrm{~min}^{-1}\right)$ & 51.0 & 6.4 \\
\hline
\end{tabular}

guidelines (American College of Sports Medicine 2000). All volunteers were also subjected to a modified Bruce treadmill test to exhaustion to elicit maximal oxygen intake $\left(\dot{V} \mathrm{O}_{2 \max }\right)$ (Koutedakis et al. 1992). The test commenced at $9 \mathrm{~km} \mathrm{~h}^{-1}$ with 2 min speed increments of $1 \mathrm{~km} \mathrm{~h}^{-1}$ until exhaustion. Following these initial stages, each subject subsequently underwent three different experimental conditions, in a random order, separated by at least 1 week of resting: (1) a 60-min WL at $70-75 \%$ of $1-\mathrm{RM}$, (2) a $60-\mathrm{min}$ treadmill $\mathrm{R}$ at an intensity corresponding to $70-75 \%$ of their $\dot{V} \mathrm{O}_{2 \max }$, and (3) a control period (rest). Subjects filled a questionnaire (Jamurtas et al. 2000) to monitor their delayed onset muscle soreness (DOMS) pre-, 10, 24, 48, and $72 \mathrm{~h}$ postexercise. REE and substrate utilisation were also monitored at the same time-points, as detailed below. The design of the study is summarised in Fig. 1.

\section{REE assessment}

Baseline measurements were obtained with subjects in a supine position on a comfortable bed. Data were collected for $40 \mathrm{~min}$ by the open-circuit dilution method using a metabolic cart (Vmax29; Sensormedics, USA), which was calibrated before each test using standard gases of known concentration. Energy expenditure was calculated using the Weir equation (Weir 1949) and was expressed per $24 \mathrm{~h}$. These procedures were also repeated at 10, 24, 48 and $72 \mathrm{~h}$ following baseline measurements. Apart from at $10 \mathrm{~h}$, all remaining measurements were performed between 8.00 and 10.00 a.m., following 10-12 h overnight fast, in a semi-darkened and thermoregulated room $\left(22 \pm 1{ }^{\circ} \mathrm{C}\right)$. To minimise the possible confounding influence of dietary-induced thermogenesis at the 10-h assessment, subjects were instructed to abstain from eating for $4 \mathrm{~h}$.

\section{Substrate utilisation}

Fat and carbohydrate oxidation was determined indirectly by monitoring the respiratory exchange ratio $(R)$. $R$ was determined through subjects' breathing samples that were analysed by the metabolic cart.

\section{Weight-lifting exercise}

An exercise protocol previously used (Melby et al. 1993) has been adopted. Briefly, subjects performed four sets 


\begin{tabular}{|c|c|c|c|c|c|c|}
\hline \multicolumn{4}{|c|}{$\begin{array}{l}1^{\text {st }} \text { day nutritional } \\
\text { assessment }\end{array}$} & & $\begin{array}{l}2^{\text {nd }} \text { day nutritional } \\
\text { assessment }\end{array}$ & $\begin{array}{l}3^{\text {rd }} \text { day nutritional } \\
\text { assessment }\end{array}$ \\
\hline $\begin{array}{l}\text { Baseline } \\
\text { measurement } \\
\text { (REE-RER), } \\
\text { Blood } \\
\text { drawing }\end{array}$ & $\begin{array}{l}\text { Exercise } \\
\text { (WL or R) } \\
\text { or resting }\end{array}$ & $\begin{array}{l}\text { No food } \\
\text { intake for } \\
4 \mathrm{hrs}\end{array}$ & $\begin{array}{l}10 \text { hrs } \\
\text { measurement } \\
\text { (REE-RER) }\end{array}$ & $\begin{array}{l}24 \text { hrs } \\
\text { measurement } \\
\text { (REE-RER), } \\
\text { Blood } \\
\text { drawing }\end{array}$ & $\begin{array}{l}48 \text { hrs } \\
\text { measurement } \\
\text { (REE-RER), } \\
\text { Blood } \\
\text { drawing }\end{array}$ & $\begin{array}{l}72 \text { hrs } \\
\text { measurement } \\
\text { (REE-RER), } \\
\text { Blood } \\
\text { drawing }\end{array}$ \\
\hline
\end{tabular}

Fig. 1 Design of the study. REE Resting energy expenditure, RER respiratory exchange ratio, $W L$ weight-lifting, $R$ running exercise

of ten different weight-lifting exercises. The intensity of each lift was set between $70 \%$ and $75 \%$ of their preestablished 1-RM. Subjects were instructed to perform as many repetitions as possible in a set. The usual number of lifts before failure was between 8 and 12 . The protocol included both upper and lower body exercises: bench press and bent over row, leg extensions and leg curls, bicep curls and triceps extensions, half-squats and lateral raises, military press and sit-ups. All exercises were performed using TechnoGym (USA) equipment.

\section{Aerobic exercise}

Subjects were instructed to run for $60 \mathrm{~min}$ at an intensity corresponding to $70-75 \% \dot{V} \mathrm{O}_{2 \max }$. Expired gas samples were taken every $10 \mathrm{~min}$ to ensure the prescribed exercise intensity. The average running intensity was $72.1 \%$ of $\dot{V} \mathrm{O}_{2 \max }$. Water was provided ad libitum during exercise.

\section{Nutritional assessment}

Subjects were instructed to follow their usual eating habits during the days of data collection. Furthermore, following the baseline assessment, they were asked to monitor for 3 days the type and portion of foods they consumed daily. Each subject was provided with a written set of guidelines for monitoring dietary consumption. A record sheet was provided along with instructions for recording food intake.

\section{Biochemical analyses}

Blood samples were drawn from an antecubital vein into plain evacuated test tubes. The blood was allowed to clot at room temperature for $30 \mathrm{~min}$ and centrifuged at $1,000 \mathrm{~g}$ for $10 \mathrm{~min}$. The serum layer was removed and frozen at $-20^{\circ} \mathrm{C}$ until analysis. Creatine kinase $(\mathrm{CK})$ was determined spectrophotometrically in duplicate using a commercially available kit (meg-sl-600c; Megalab, Greece). Thyroid hormones $\left(\mathrm{T}_{3}, \mathrm{~T}_{4}\right)$ were analysed by ELISA also using commercially available kits (Roche kits, Cat. No. 11731360 and 11731297 for $T_{3}$ and $T_{4}$, respectively). Intra-assay and inter-assay coefficiency for CK was $6.5 \%$ and $7.1 \%$, respectively. The corresponding measurements for $\mathrm{T}_{3}$ and $\mathrm{T}_{4}$ were $4.5 \%$ and $5.3 \%$, and $5.4 \%$ and $6.1 \%$ for the two thyroid hormones, respectively.

\section{Statistical analysis}

One-way repeated measures MANOVA with planned contrasts was performed for each group separately, using the Statistical Package for Social Sciences (version 8.0). The level of significance was set at $P<0.05$.

\section{Results}

Results from the nutritional assessment revealed that there were no significant differences over time in energy intake or the proportion of foods, in any of the three conditions (Table 2). Sixty minutes of WL and aerobic $\mathrm{R}$ resulted in significantly elevated REE $10 \mathrm{~h}$ post exercise compared to corresponding baseline data. Furthermore, REE remained elevated 24 and $48 \mathrm{~h}$ after WL and R, respectively (Table 3). No significant changes were observed over time for REE in the control session $(P>0.05)$.

$R$ was significantly lower than the baseline values at 10 and $24 \mathrm{~h}$ post-exercise for both exercise conditions. No significant changes were observed over time for $R$ in the control session $(P>0.05)$ (Table 4).

Table 2 Nutritional assessment results after a single bout of exercise ( $W L$ weight-lifting, $R$ running, $C$ control, $C H O$ carbohydrates). Data presented as mean (SEM)

\begin{tabular}{|c|c|c|c|c|c|c|c|c|c|}
\hline & \multicolumn{3}{|l|}{ 1st day } & \multicolumn{3}{|l|}{ 2nd day } & \multicolumn{3}{|l|}{ 3rd day } \\
\hline $\mathrm{CHO}(\%)$ & $47.4(3.1)$ & $48.6(5.3)$ & $46.3(5.7)$ & $43.6(2.6)$ & $47.4(2.3)$ & $48.5(3.6)$ & $48.0(3.4)$ & $44.2(3.5)$ & $49.2(2.8)$ \\
\hline Fat $(\%)$ & $38.5(3.2)$ & $37.9(5.2)$ & $38.3(6.7)$ & $40.7(2.5)$ & $39.1(3.0)$ & $39.1(3.0)$ & $36.2(3.2)$ & $40.4(3.5)$ & $35.6(2.9)$ \\
\hline Protein $(\%)$ & $14.1(0.8)$ & $13.5(0.9)$ & 15.4 (1.6) & $15.7(1.0)$ & $13.5(1.4)$ & $12.4(0.9)$ & $15.8(1.6)$ & $15.4(0.8)$ & $15.2(1.0)$ \\
\hline
\end{tabular}


Table 3 Resting energy expenditure (REE; kcal) changes after a single bout of exercise (Pre baseline data). Data presented as mean (SEM)

\begin{tabular}{llllll}
\hline & Pre & 10 & 24 & 48 & 72 \\
\hline WL & $1972(82)$ & $2124(78)^{*}$ & $2081(76)^{*}$ & $1997(88)$ & $1897(84)$ \\
R & $1862(70)$ & $2150(73)^{*}$ & $1914(109)$ & $1995(74)^{*}$ & $1958(93)$ \\
C & $1865(73)$ & $1875(79)$ & $1848(56)$ & $1817(57)$ & $1942(113)$
\end{tabular}

*Significantly different compared to Pre $(P<0.05)$

CK and DOMS data are presented in Table 5. CK values were significantly elevated $24 \mathrm{~h}$ after the end of both exercise sessions. Furthermore, DOMS was significantly elevated $24 \mathrm{~h}$ following the WL session. No significant differences were observed during the posttreatment measurements for $\mathrm{R}$ and control conditions. Finally, Table 6 illustrates no significant differences in the thyroid hormone levels at any time point examined during the three conditions $(P>0.05)$.

\section{Discussion}

The aim of this study was to determine whether there is a significant perturbation in REE and substrate utilisation after a single bout of either resistance or aerobic exercise of the same relative intensity and duration. The results indicate that REE and fat oxidation are altered after both exercise conditions. The perturbation in REE following WL lasted $24 \mathrm{~h}$ post-exercise, whereas REE changes after $\mathrm{R}$ seem to follow a biphasic pattern.

Results from our study are in partial agreement with previous research findings, which indicate that acute resistance exercise of similar to this study's intensity (i.e. $75 \%$ of $1-\mathrm{RM}$ ) resulted in significant elevation of REE up to $48 \mathrm{~h}$ post-exercise (Schuenke et al. 2002). In contrast, similar studies have shown that the perturbations in REE do not last longer than $1 \mathrm{~h}$ after WL exercise (Elliot et al. 1992; Haltom et al. 1999). However, unlike the present investigation, these latter studies utilised exercise protocols which were either very low $(50 \%$ of $1-\mathrm{RM})$ or very heavy $(90 \%$ of $1-\mathrm{RM})$ in resistance. It could be argued, therefore, that our moderate resistance exercise can induce perturbation in REE that have longer effects compared to resistance exercise of either low or heavy intensity.

Regarding the single bout of running exercise, our data contradict previous research indicating that downhill running (Thomas et al. 1994) and level treadmill jogging (Kolkhorst et al. 1994) bring about no REE changes beyond $24 \mathrm{~h}$ post-exercise. Contrary to these, Bahr and Sejersted (1991) have shown that acute aerobic
Table 5 Creatine kinase $\left(C K\right.$; IU $\left.1^{-1}\right)$ and delayed onset muscle soreness $(D O M S)$ changes after a single bout of exercise. Data presented as mean (SEM)

\begin{tabular}{|c|c|c|c|c|c|c|}
\hline & \multicolumn{3}{|l|}{ CK } & \multicolumn{3}{|l|}{ DOMS } \\
\hline & WL & $\mathrm{R}$ & $\mathrm{C}$ & WL & $\mathrm{R}$ & $\mathrm{C}$ \\
\hline Pre & $103(29)$ & 94 (18) & $84(14)$ & $1(0)$ & $1(0)$ & $1(0)$ \\
\hline 24 & $184(39) *$ & $244(75)^{*}$ & $101(37)$ & $2.8(0.4)^{*}$ & $1(0)$ & $1(0)$ \\
\hline 48 & $108(20)$ & 168 (77) & 89 (21) & $1.6(0.3)$ & $1(0)$ & $1(0)$ \\
\hline 72 & 124 (73) & 121 (47) & $92(25)$ & $3.1(0.7)$ & $1(0)$ & $1(0)$ \\
\hline
\end{tabular}

*Significantly different compared to Pre $(P<0.05)$

exercise performed at an intensity similar to that of the present study (i.e. $75 \% \quad \dot{V} \mathrm{O}_{2 \max }$ resulted in increased excess post-exercise oxygen consumption for $5 \mathrm{~h}$. Also, Bielinski et al. (1985) reported significantly elevated REE levels $24 \mathrm{~h}$ after a 3-h aerobic exercise at $50 \%$ $\dot{V} \mathrm{O}_{2 \max }$. In the present study, although REE changes after $\mathrm{R}$ revealed a biphasic pattern, an overall $8.5 \%$ increase above the baseline data was noted up to $48 \mathrm{~h}$ post-exercise.

There are several factors that could affect REE levels following an acute bout of exercise. For instance, elevated protein degradation and reparation that takes place after such exercise (Clarkson and Sayers 1999; Kuipers 1994) can bring about augmentation in REE, which could be attributed to exercise-induced muscle damage (Binzen et al. 2001). The associated protein resynthesis is energetically taxing on REE (MacDougal et al. 1995), resulting in an up to $20 \%$ increase in resting metabolism (Welle and Nair 1990).

Changes in serum thyroid hormone levels or activity and the related thermogenesis have been proposed as additional factors affecting REE. However, changes in thermogenesis, as depicted by the thyroid hormone levels, cannot account for the present REE perturbations since the levels of $T_{3}$ and $T_{4}$ were not significantly changed over time.

Increased sympathetic nervous system activity has also been included in the factors affecting REE. Leuenberger et al. (1993) reported higher spillover and lower clearance of norepinephrine after moderate- to highintensity aerobic exercise. Indeed, heightened norepinephrine discharge from nerve endings, in conjunction with lower clearance from the circulation, can lead to greater serum levels of this hormone, which could account for the improved beta-adrenergic stimulation (Yoshika et al. 2001) and elevation in REE (Pratley et al. 1994). We could assume, therefore, that increased sympathetic nervous system activity could partly explain the current REE levels found 10 and $48 \mathrm{~h}$ after an aerobic session. To our knowledge, no studies have yet examined
Table 4 Respiratory exchange ratio changes after a single bout of exercise. Data presented as mean (SEM)

*Significantly different compared to Pre $(P<0.05)$

\begin{tabular}{llllll}
\hline & Pre & 10 & 24 & 48 & 72 \\
\hline WL & $0.870(0.025)$ & $0.813(0.043)^{*}$ & $0.843(0.040)^{*}$ & $0.867(0.044)$ & $0.881(0.030)$ \\
R & $0.876(0.04)$ & $0.818(0.021)^{*}$ & $0.832(0.021)^{*}$ & $0.870(0.036)$ & $0.868(0.038)$ \\
$\mathrm{C}$ & $0.868(0.014)$ & $0.878(0.023)$ & $0.861(0.019)$ & $0.887(0.013)$ & $0.876(0.018)$ \\
\hline
\end{tabular}


Table 6 Thyroid hormone $\left(\mathrm{T}_{3}\right.$ and $\mathrm{T}_{4} ; \mathrm{ng} \mathrm{ml}^{-1}$ ) levels after a single bout of exercise. Data presented as mean (SEM)

\begin{tabular}{|c|c|c|c|c|c|c|}
\hline & \multicolumn{3}{|l|}{$\mathrm{T}_{3}$} & \multicolumn{3}{|l|}{$\mathrm{T}_{4}$} \\
\hline & WL & $\mathrm{R}$ & $\mathrm{C}$ & WL & $\mathrm{R}$ & $\mathrm{C}$ \\
\hline Pre & $1.33(0.06)$ & $1.42(0.04)$ & $1.48(0.14)$ & $1.53(0.08)$ & $1.58(0.09)$ & $1.59(0.11)$ \\
\hline 24 & $1.31(0.06)$ & $1.36(0.06)$ & $1.48(0.11)$ & $1.48(0.09)$ & $1.52(0.08)$ & $1.63(0.10)$ \\
\hline 48 & $1.29(0.06)$ & $1.35(0.04)$ & $1.47(0.14)$ & $1.49(0.08)$ & $1.48(0.07)$ & $1.63(0.14)$ \\
\hline 72 & $1.35(0.07)$ & $1.41(0.04)$ & $1.48(0.16)$ & $1.57(0.09)$ & $1.53(0.07)$ & $1.60(0.15)$ \\
\hline
\end{tabular}

relationships between weight-lifting, norepinephrine, beta-adrenergic stimulation and REE.

An alternate explanation for the elevated REE after a single bout of exercise could be a shift in substrate utilisation. Indirect evaluation of substrate use in the current study, measured by changes in $R$, demonstrated a clear shift toward lipid utilisation. $R$ was lower at 10 and $24 \mathrm{~h}$ post-exercise in both exercise conditions. It is known that strenuous exercise depends on anaerobic metabolism of the phosphagen system and glycogenolysis, which leads to glycogen depletion (American College of Sports Medicine 1998). During recovery from such exercise, lipid becomes the predominant fuel while carbohydrate use is spared for glycogen repletion. Therefore, a drop in $R$, which is associated with an increased lipid utilisation in the recovery period, normally indicates the body's attempt to replenish the depleted glycogen stores.

In conclusion, and within the limits of the present investigation, the current data demonstrated that REE can be significantly elevated 24 and $48 \mathrm{~h}$ following a single session of WL and R exercise, respectively. These data also indicated a shift in substrate utilisation towards enhanced lipid oxidation, following both exercise modes. Such enhanced energy expenditure and lipid oxidation levels during recovery from exercise might play an important role in body-mass-control regimes.

\section{References}

American College of Sports Medicine (1998) Resource manual for guidelines for exercise testing and prescription, 3rd edn. Lippincott Williams and Wilkins, Baltimore

American College of Sports Medicine (2000) Guidelines for exercise testing and prescription, $6^{\text {th }}$ edn. Lippincott Williams and Wilkins, Baltimore

Bahr R, Sejersted OM (1991) Effect of intensity of exercise on excess post-exercise $\mathrm{O}_{2}$ consumption. Metabolism 40:836-841

Bielinski R, Schutz Y, Jequier E (1985) Energy metabolism during the post-exercise recovery in man. Am J Clin Nutr 42:69-82

Binzen CA, Swan PD, Manore MM (2001) Postexercise oxygen consumption and substrate use after resistance exercise in women. Med Sci Sports Exerc 33:932-938

Bullough RC, Gillette CA, Harris MA, Melby CL (1995) Interaction of acute changes in exercise energy expenditure and energy intake on resting metabolic rate. Am J Clin Nutr 61:473-481

Burleson MA, O'Bryant HS, Stone MH, Collins MA, TriplettMcBride T (1998) Effect of weight training exercise and treadmill exercise on post-exercise oxygen consumption. Med Sci Sports Exerc 30:518-522

Clarkson PM, Sayers SP (1999) Etiology of exercise-induced muscle damage. Can J Appl Physiol 24:234-248
Dolezal BA, Potteiger JA (1998) Concurrent resistance and endurance training influence basal metabolic rate in nondieting individuals. J Appl Physiol 85:695-700

Elliot DL, Goldberg L, Kuehl KS (1992) Effects of resistance training on excess post-exercise oxygen consumption. J Appl Sports Sci Res 6:77-81

Haltom RW, Kraemer RR, Sloan RA, Hebert EP, Frank K, Tryniecki JL (1999) Circuit weight training and its effects on excess post-exercise oxygen consumption. Med Sci Sports Exerc 31:1613-1618

Jamurtas AZ, Fatouros JG, Buckenmeyer PJ, Kokkinidis E, Taxildaris K, Kambas A, Kyriazis G (2000) Effects of plyometric exercise on muscle soreness and creatine kinase levels and its comparison to eccentric and concentric exercise. J Strength Cond Res 14:68-74

Kolkhorst FW, Londeree BR, Thomas TR (1994) Effects of consecutive exercise days of jogging or cycling on the resting metabolic rate and nitrogen balance. J Sports Med Phys Fitness $34: 343-350$

Koutedakis Y, Boreham C, Kabitsis C, Sharp NC (1992). Seasonal deterioration of selected physiological variables in elite male skiers. Int J Sports Med 13:548-551

Kuipers H (1994) Exercise-induced muscle damage. Int J Sports Med 10:272-278

Lebon V, Dufour S, Petersen KF, Ren J, Jucker BM, Slezak LA, Cline GW, Rothman DL, Shulman GI (2001) Effect of triiodothyronine on mitochondrial energy coupling in human skeletal muscle. J Clin Invest 108:733-737

Leuenberger U, Sinoway L, Gubin S, Gaul L, Davis D, Zelis R (1993) Effects of exercise intensity and duration on norepinephrine spillover and clearance in humans. J Appl Physiol 75:668-674

MacDougall JD, Gibala MJ, Tarnopolsky MA, MacDonald JR Interisano SA, Yarasheski KE (1995) The time-course for elevated muscle protein synthesis following heavy resistance exercise. Can J Appl Physiol 20:480-486

Melby C, Scholl C, Edwards G, Bullough R (1993) Effect of acute resistance exercise on post-exercise energy expenditure and resting metabolic rate. J Appl Physiol 75:1847-1853

Poehlman ET, Melby C (1998) Resistance training and energy balance. Int J Sport Nutr 8:143-59

Poehlman ET, Gardner AW, Ades PA, Katzman-Rooks SM, Montgomery SM, Atlas OK, Ballor DL, Tyzbir RS (1992) Resting energy metabolism and cardiovascular disease risk in resistance-trained and aerobically trained males. Metabolism 41:1351-1360

Pratley R, Nicklas B, Rubin M, Miller J, Smith A, Smith M, Hurley B, Goldberg A (1994) Strength training increases resting metabolic rate and norepinephrine levels in healthy 50- to 65year-old men. J Appl Physiol 76:133-137

Schuenke MD, Mikat RP, McBride JM (2002) Effect of an acute period of resistance exercise on excess post-exercise oxygen consumption: implications for body mass management. Eur J Appl Physiol 86:411-417

Sedlock DA, Fissinger JA, Melby CL (1989) Effect of exercise intensity and duration on post-exercise energy expenditure. Med Sci Sports Exerc 21:662-666

Thomas TR, Londeree BR, Lawson DA (1994) Prolonged recovery from eccentric versus concentric exercise. Can J Appl Physiol 19:441-450 
Weir JB (1949) New methods for calculating metabolic rate with special reference to protein. J Physiol (Lond) 109:1-9

Welle S, Nair KS (1990) Relationship of resting metabolic rate to body composition and protein turnover. Am J Physiol 258:E990-998

Williamson DL, Kirwan JP (1997) A single bout of concentric resistance exercise increases basal metabolic rate 48 hours after exercise in healthy 59- to 77-year-old men. J Gerontol A Biol Sci Med Sci 52:M352-355
Yoshika M, Doucet E, St-Pierre S, Almeras N, Richard D, Labrie A, Despres JP, Bouchard C, Tremblay A (2001) Impact of highintensity exercise on energy expenditure, lipid oxidation ad body fatness. Int $\mathbf{J}$ Obes 25:332-339 